\title{
EFFECT OF STORAGE ON RESIDUE LEVELS OF ENROFLOXACIN IN MUSCLE OF RAINBOW TROUT (ONCORHYNCHUS MYKISS) AND COMMON CARP (CYPRINUS CARPIO)
}

\author{
Ralica Kyuchukova $^{1}$, Anelia Milanova ${ }^{2}$, Aleksandra Daskalova ${ }^{1}$, \\ Deyan Stratev ${ }^{1}$, Lubomir Lashev², Alexander Pavlov ${ }^{1}$ \\ ${ }^{1}$ Department of Hygiene and Technology of Foods, \\ Faculty of Veterinary Medicine, Trakia University, Bulgaria \\ ${ }^{2}$ Department of Pharmacology, Physiology of Animals and Physiological Chemistry, \\ Faculty of Veterinary Medicine, Trakia University, Bulgaria
}

Received 23 September 2015; Received in revised form 5 January 2016; Accepted 25 January 2016

\begin{abstract}
Since fluoroquinolones are one of the most commonly used antibacterial drugs in aquaculture, there is a risk of their residues to be found in the treated fish. The objective of this study was to examine the changes in enrofloxacin and ciprofloxacin levels during storage of rainbow trout and common carp muscle at $-18{ }^{\circ} \mathrm{C}$. The trout and carp were treated orally with a single dose of $10 \mathrm{mg} / \mathrm{kg}$ of enrofloxacin. Tissue samples were collected $24 \mathrm{~h}$ after the treatment and stored at $-18{ }^{\circ} \mathrm{C}$ for 270 days either as a whole fish or as precut muscle samples. Results for trout revealed that in the precut samples enrofloxacin concentration decreased significantly only after 9 months of storage, whereas a significant decline in the ciprofloxacin level was observed much earlier (after 3 months). After 9 months of storage, the trout stored without being sliced and eviscerated showed significantly higher levels of both quinolones as compared to the precut muscle samples. The enrofloxacin levels in the carp musculature decreased considerably after 3 months of storage and stayed almost unchanged up to the end of the study, whereas the ciprofloxacin concentration continued to drop even after this period and after 270 days constituted 1/6 of the initial values.
\end{abstract}

Key words: ciprofloxacin, common carp, enrofloxacin, rainbow trout, residues, storage

\section{INTRODUCTION}

Fluoroquinolones are a group of synthetic antimicrobial agents widely used in human and veterinary medicine for treatment and prevention of infections caused by Gram-negative and Grampositive bacteria (1). They are among the most often prescribed antibiotics in fisheries (2), but their use in aquaculture presents a risk to fish products' consumers, because of potential risk of residues in the food. Tissue disposition of fluoroquinolones, including enrofloxacin and ciprofloxacin, in fish species depends on several factors such as ambient

Corresponding author: Assoc. Prof. Ralica Kyuchukova, $\mathrm{PhD}$ E-mail address: ralitsa.kjuchukova@abv.bg Present address: Department of Hygiene and Technology of Foods, Faculty of Veterinary Medicine, Trakia University, Bulgaria Phone: ++ 359897505716

Copyright: (C) 2016 Kyuchukova R. This is an open-access article published under the terms of the Creative Commons Attribution License which permits unrestricted use, distribution, and reproduction in any medium, provided the original author and source are credited. Competing Interests: The authors have declared that no competing interests exist.

Available Online First: 5 February 2016

Published on: 15 March 2016

http://dx.doi.org/10.1515/macvetrev-2016-0076 water temperature and salinity, lipid content and properties of the drug molecule $(3,4)$. These factors have significant impact on the withdrawal time and depletion of residues from muscles and can be a prerequisite for the presence of undesirable levels of drugs. Information about the behavior of residues of antibiotics during frozen storage is scarce. Alfredson and Ohlsson (5) found significant reduction of sulfamethazine residues in muscle kept for 3 months at a temperature of $-20^{\circ} \mathrm{C}$. The average decrease was $35 \%$ in bovine and $55 \%$ in porcine muscle (5). Other data showed a significant decrease of ampicillin residues in pork meat during the first 3 months of storage at $-20^{\circ} \mathrm{C}(6)$. Residual concentrations of ampicillin were found in the pork muscles after 8 months of storage at the same temperature (6). In our previous studies major reduction of the residues of amoxicillin (7), kanamycin (8), tobramycin (9), and ampicillin (10) in poultry or rabbit meat during storage at $-18^{\circ} \mathrm{C}$ was found. No significant reduction of trimethoprim in poultry meat (8) and gentamicin in rabbit meat was registered (10). In all cases, microbiological methods were used which 
limited the ability for detection of metabolites. This data shows that stability of antibacterial substances in mammals' and chickens' muscles differs significantly, depending on the individual drug and animal species. Moreover, little is known of the stability of antimicrobial drugs in fish muscle after different storage times at usual commercial conditions.

Because of insufficient data concerning the changes of antimicrobial residues in meat during storage, the aim of the present study was to investigate concentration changes in enrofloxacin and its metabolite ciprofloxacin contents in trout and carp meat during frozen storage.

\section{MATERIAL AND METHODS}

\section{Drugs}

Enrofloxacin (Baytril 5\%, Part. No KP076SM, Bayer Animal Health Gmbh, Leverkuzen, Germany) was used for oral (p.o.) treatment of fish as $1 \%$ solution. Analytical standards of enrofloxacin hydrochloride (Part No. 20020323) and ciprofloxacin hydrochloride (Part No. FPCPF 070483) were supplied by Biovet Pestera (Bulgaria) and Actavis (Bulgaria), respectively.

\section{Animals}

Two years old rainbow trouts (Oncorhynchus mykiss, $\mathrm{n}=20$ ) with mean body weight of $450 \mathrm{~g}$ were included in the experiments. They were supplied by a fish farm, located in Enina (Bulgaria). The animals were placed in two aerated tanks. Water temperature was $15^{\circ} \mathrm{C}$ and $\mathrm{pH}$ was 7.5 .

Market-sized carps (Cyprinus carpio, $\mathrm{n}=11$ ) with a mean body weight of $1000 \mathrm{~g}$ were purchased from a commercial fish farm in Nikolaevo (Bulgaria). The fish were placed in 2 tanks, containing 8001 of tap water (water temperature $17^{\circ} \mathrm{C} ; \mathrm{pH} 7.2$ ) with constant aeration.

\section{Experimental procedure}

The experimental design was approved by the Ethics and Animal Welfare Committee at Trakia University, Stara Zagora. Euthanasia was performed under the Directive 2010/63/EU on the protection of animals used for scientific purposes requirements.

Control groups of trouts $(n=5)$ and carps $(n=5)$ were not treated with enrofloxacin and were used for obtaining of muscle tissue samples for preparation of blank samples and fortified samples with standard dilutions for quantitative analysis of the drugs.

The other trouts $(n=15)$ and carps $(n=6)$ were treated orally with a single dose of enrofloxacin via 98 a gavage tube $(1 \%$ solution at dose rate of $10 \mathrm{mg} / \mathrm{kg}$ body weight). Tissue samples were obtained from each fish after euthanasia by a percussive (manual) blow on the cranium with a hammer. Muscle samples were taken from six fishes from each species 24 hours after the treatment with the antibacterial agent. Each muscle sample was divided into six portions and they were stored at $-18{ }^{\circ} \mathrm{C}$. These samples were analyzed at day 0 (immediately after obtaining the samples), 15, 30, 90, 180 and 270 of the storage. The remaining 9 trouts were euthanized and stored as whole fishes (with internal organs), without cleaning and muscle samples were analyzed 180 and 270 days after the storage. Aqueous solutions of enrofloxacin hydrochloride and ciprofloxacin hydrochloride $(1 \mathrm{mg} / \mathrm{mL})$ were stored at the same conditions as samples for depletion check of the pure standards. These solutions were analyzed together with the muscle samples at the same time intervals.

HPLC analysis of enrofloxacin and ciprofloxacin concentrations

The tissue samples from muscles $(0.5 \mathrm{~g})$ were homogenized in $0.5 \mathrm{~mL}$ of $0.1 \mathrm{M}$ phosphate buffer $\mathrm{pH} 7.4$ with a homogenizer at high speed up to 1 min. To this homogenate, $6 \mathrm{~mL}$ of dichloromethane were added, and the samples were mixed for $1 \mathrm{~min}$ and centrifuged for $6 \mathrm{~min}$ at $1000 \mathrm{xg}$. The aqueous layer was removed. The organic phase was collected in $10 \mathrm{ml}$ tubes. It was evaporated in a vacuum evaporator (CentriVap Vacuum Concentration System, Labconco, Kansas, MO, USA) at $40{ }^{\circ} \mathrm{C}$ to dryness. The residue was dissolved in $500 \mu \mathrm{L}$ of demineralized water. Aliquots from $20 \mu \mathrm{L}$ were injected into the HPLC system.

HPLC system was equipped with Hypersil Spherisorb ODS-2 (C18)-150 4.6 -mm $5 \mu \mathrm{M}$ column, a Surveyor LC Pump Plus, a Surveyor fluorescence detector, and a Surveyor Autosampler Plus (Thermo Fisher Scientific Inc., USA). The column was used at room temperature. The mobile phase consisted of acetonitrile in aqueous solution $(25: 75, \mathrm{v} / \mathrm{v})$ of potassium dihydrogen phosphate $(0.05 \mathrm{M})$ in water. The $\mathrm{pH}$ of the mobile phase was adjusted to 3.5 with phosphoric acid (85\%). The flow rate was $0.6 \mathrm{~mL} / \mathrm{min}$, isocratic conditions. Excitation and emission wavelengths were set at $277 \mathrm{~nm}$ and $418 \mathrm{~nm}$, respectively for determination of enrofloxacin and ciprofloxacin. Peak area integrations were carried-out using ChromQuest Chromatography Data System (Thermo Fisher Scientific Inc., USA). Standard curves for both fluororquinolones were prepared with tissues from untreated animals. The concentrations of calibration standards for enrofloxacin and ciprofloxacin were 1000, 750, 
Effect of storage on enrofloxacin residue levels in muscle of trout and carp

Table 1. Residues of enrofloxacin and ciprofloxacin in muscle samples (Mean $\pm \mathrm{SD}$ ) from trout (Oncorhinchus mykiss) and carp (Cyprinus carpio) after storage at $-18^{\circ} \mathrm{C}$

\begin{tabular}{ccc}
\hline Day of storage & Enrofloxacin $(\boldsymbol{\mu g} / \mathbf{g})$ & Ciprofloxacin $(\boldsymbol{\mu g} / \mathbf{g})$ \\
\hline & Oncorhinchus mykiss & \\
15 & $5.94 \pm 4.89$ & $0.58 \pm 0.24$ \\
30 & $5.60 \pm 3.62$ & $0.47 \pm 0.30$ \\
90 & $5.43 \pm 4.19$ & $0.47 \pm 0.39$ \\
180 & $5.46 \pm 5.07$ & $0.30 \pm 0.23^{*}$ \\
270 & $5.71 \pm 6.26$ & $0.31 \pm 0.15^{*}$ \\
& $3.69 \pm 4.17$ & $0.23 \pm 0.12^{*}$ \\
\hline 0 & Cyprinus carpio & \\
15 & $1.27 \pm 1.76$ & $0.36 \pm 0.45$ \\
90 & $1.20 \pm 0.64$ & $0.36 \pm 0.48$ \\
180 & $1.10 \pm 0.64$ & $0.34 \pm 0.12$ \\
270 & $0.41 \pm 0.30$ & $0.10 \pm 0.02^{*}$ \\
\hline
\end{tabular}

*Statistically significant differences in comparison to the concentrations at day of storage 0 at $\mathrm{P}<0.05$

500, 250, 100, 50, and $10 \mathrm{ng} / \mathrm{mL}$. Retention times for enrofloxacin and ciprofloxacin were $3.88 \mathrm{~min}$ and $4.57 \mathrm{~min}$, respectively. Limit of detection and limit of quantification for both compounds were 10 and $50 \mathrm{ng} / \mathrm{mL}$. The overall recovery rate in tissue samples exceeded $>75 \%$.

The analysis was performed in the Central Scientific Laboratory of Trakia University.

\section{Statistical analysis}

Descriptive statistics was performed with Statistica for Windows (Statistica 6.0.1, USA). Data were presented as mean $\pm \mathrm{SD}$. Statistical analysis was performed with Mann-Whitney test. - P level $<0.05$ was considered as significant.

\section{RESULTS}

\section{Rainbow trout (Oncorhynhus mykiss)}

Enrofloxacin residues in the meat of rainbow trout showed insignificant decrease during frozen storage the first six months (Table 1). Considerable decrease was observed after storage during the last 3 months, after 270 days of storage. The levels reached $3.69 \mu \mathrm{g} / \mathrm{g}$, or $62 \%$ of the initial values (Fig. 1).

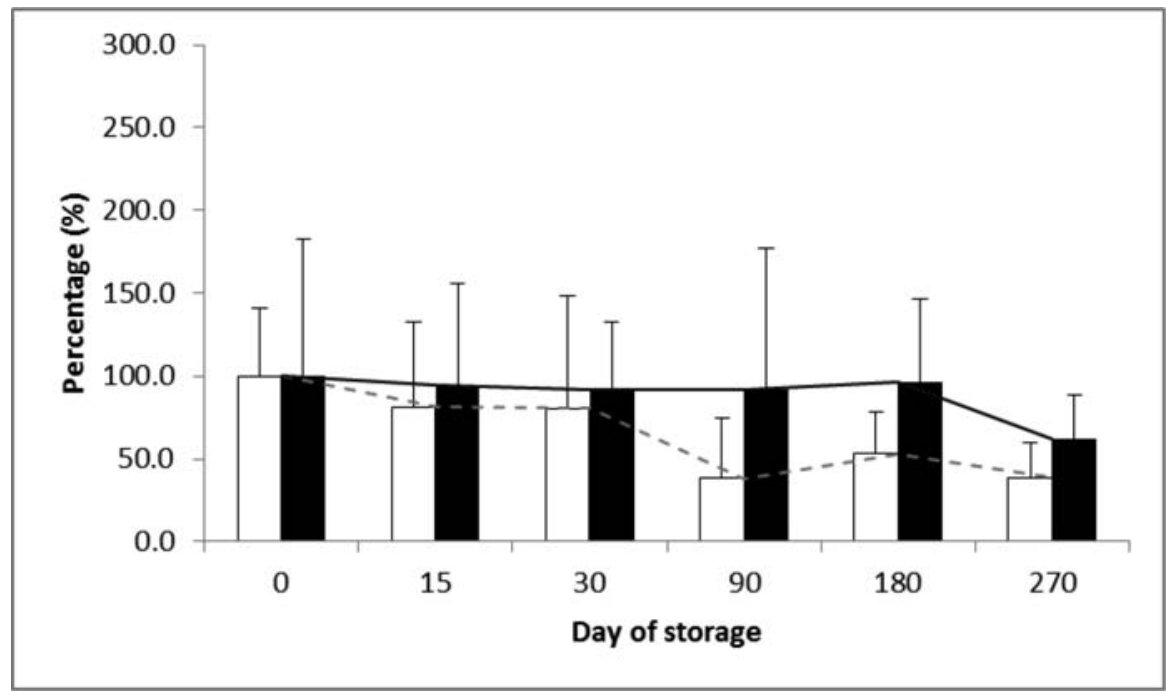

Figure 1. Levels of residues of enrofloxacin and ciprofloxacin, presented as percentage of the day 0 of storage, in muscle samples from trout (Oncorhinchus mykiss) after storage at $-18{ }^{\circ} \mathrm{C} . \square$ and gray dashed line represent data for ciprofloxacin; and black line represent data for enrofloxacin 
Ciprofloxacin, which initial concentration (at 0 day) in the trout meat constituted about $10 \%$ of the enrofloxacin level, showed tendency for a gradual decrease. During the first 2 weeks of storage a decline of approximately $19 \%$ was observed $(\mathrm{P}>0.05)$ and subsequently after 9 months of storage, the ciprofloxacin concentration in the meat was less than $50 \%$ of the initial concentration $(\mathrm{P}<0.05)$. Significantly lower ciprofloxacin levels were measured after 3 months of storage $(\mathrm{P}<0.05)$.

The fish, stored without being sliced and eviscerated, showed different tissue levels of both fluoroquinolones as compared to the muscle samples which were cut into small pieces before storage. After 9 months of storage the enrofloxacin and ciprofloxacin residues were $8.24 \pm 3.99 \mu \mathrm{g} / \mathrm{g}$ and $0.56 \pm 0.47 \mu \mathrm{g} / \mathrm{g}$, respectively. These values were higher than those obtained from the precut muscle samples $(\mathrm{P}>0.05)$. Enrofloxacin concentrations were $38 \%$ higher and the amount of ciprofloxacin was similar if compared to the initial concentrations of the drugs in the muscles.

\section{Common carp (Cyprinus carpio)}

Results obtained from the analyzed carp muscles showed that during the first month of storage there were no statistically significant changes in the tissue levels of both quinolones (Table 1). After 90 days of storage at $-18{ }^{\circ} \mathrm{C}$, enrofloxacin concentration decreased to $30 \%$ of the initial level and remained almost unchanged up to the end of the study
(Fig. 2). Ciprofloxacin level continued to drop even after 90 days of storage and at the end of the storage period its concentration constituted approximately $1 / 6^{\text {th }}$ of the initial values. Its concentrations were statistically significantly lower after 3, 6 and 9 months of storage $(\mathrm{P}<0.05)$.

\section{DISCUSSION}

Rearing of fish species in farm conditions and international trade with aquaculture products have significantly developed during the last years. These tendencies determine extensive use of antibacterial drugs to control increased rates of diseases. Enrofloxacin is among the few drugs licensed for use in aquatic species with established Maximum Residual Limits of $100 \mu \mathrm{g} / \mathrm{kg}$ as the sum of the levels of enrofloxacin and ciprofloxacin in tissues (11). Literature data indicates variable withdrawal time in different fish species (12). Therefore depletion of drugs from edible tissues must be assessed in order to offer safe food on the market. In fish species, additional obstruction is the dependence of residues depletion time on the water temperature (4). Although they adopted strict criteria, there are cases of illegal use of drugs without following the required withdrawal time and Maximum Residual Limits which can be a reason for existence of residues in processed fish and requires information about the stability of enrofloxacin and its active metabolite under conditions of storage.

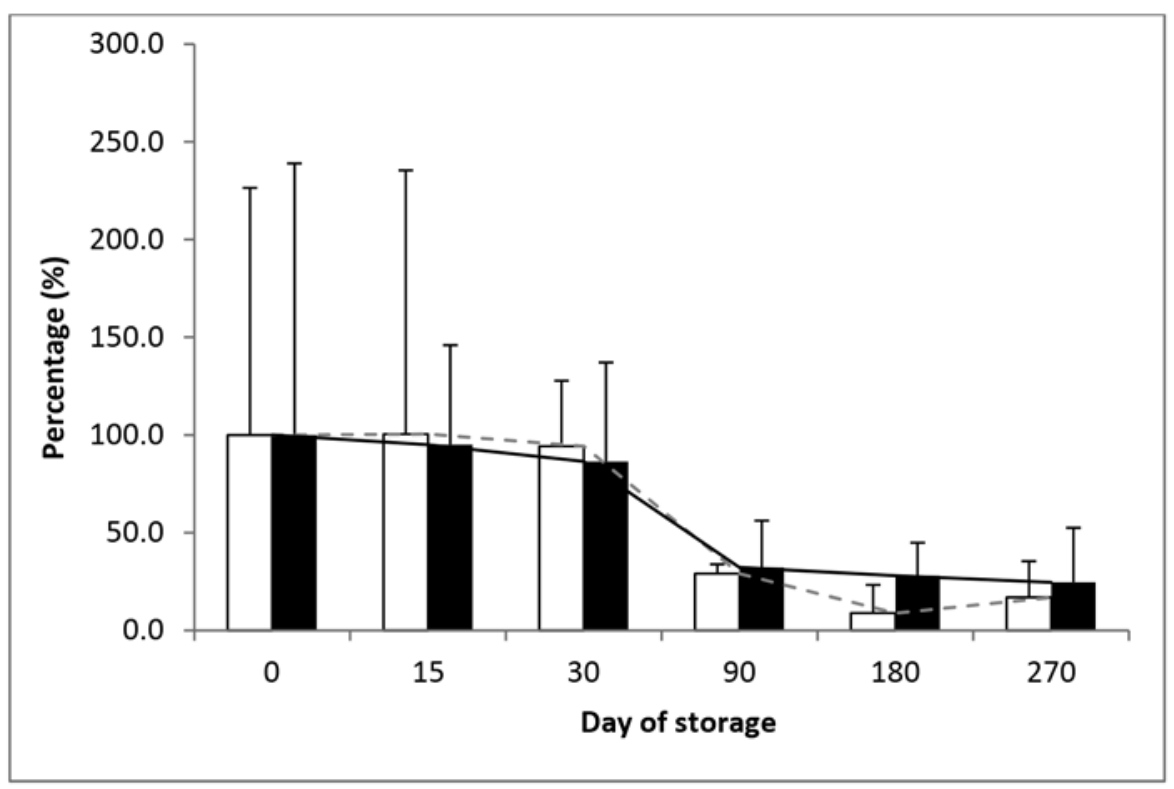

Figure 2. Levels of residues of enrofloxacin and ciprofloxacin in muscle samples from carp (Cyprinus carpio) after storage at $-18{ }^{\circ} \mathrm{C}$. Data are presented as percentage from the day 0 of storage. $\square$ and dashed gray line represent data for ciprofloxacin; $\mathbf{a}$ and black line represent data for enrofloxacin 
The data from our study show differences between trout and carp in the depletion time of fluoroquinolones after storage of muscle samples at $-18^{\circ} \mathrm{C}$. Storage of trout meat for six months resulted in absence of significant changes $(\mathrm{P}>0.05)$ of enrofloxacin residues in meat and the highest decrease was observed after nine months. Insignificant changes were found in both enrofloxacin and ciprofloxacin levels in carp muscle during the first month of storage. Significant decrease of enrofloxacin levels was observed 90 days after freezing, which was earlier in carp samples if compared to trout. Similarly to these results, the concentrations of enrofloxacin in water samples frozen at $-20^{\circ} \mathrm{C}$ for 28 days, were stored up to $90 \%$ in comparison to the samples, analyzed immediately (13). After 6 months of preservation of stock solutions of enrofloxacin at $-20^{\circ} \mathrm{C}$ the loss was less than $10 \%$ than in Rainbow trout fish meat, kept in the same freezer in the current study. After a longer period of storage, concentrations of fluoroquinolones in frozen water samples dropped off dramatically as in our experiment (14). Similar data were reported for tetracyclines, aminopenicillines and sulfonamides in frozen water in the EPA study (13) and in frozen meat samples. Verdon et al. (6) found $40 \%$ lower concentrations of ampicillin in pork meat kept at $-20^{\circ} \mathrm{C}$ for 235 days and absence of changes at $-70{ }^{\circ} \mathrm{C}$. Trimetoprim degraded up to $50 \%$ in chicken meat after freezing at $-18^{\circ} \mathrm{C}$ for 30 to 90 days (8). Gentamicin was stable in rabbit's meat stored at same conditions for 45 days (10).

Enrofloxacin is dealkylated to pharmacologically active metabolite ciprofloxacin in several fish species, including trout and carp $(15,16,17)$. Ciprofloxacin was found in the muscles of both investigated fish species and its depletion from this tissue differs from the data for the parent compound. Results showed that 15 days of storage lead to reduction of ciprofloxacin concentrations by $20 \%$ and by more than $50 \%$ after the third month till the end of the experiment in trout muscles. The observed higher concentrations of enrofloxacin and ciprofloxacin in samples from whole trout, stored with internal organs, can be explained by additional penetration of fluoroquinolones to the muscles. Depletion pattern of ciprofloxacin concentrations in the carp muscles was similar to those in the samples from trout. Similarly, another fluoroquinolone compound such as gatifloxacin was stable in human plasma for 7 weeks at $-20^{\circ} \mathrm{C}(18)$.

\section{CONCLUSION}

Our data indicates that the samples from rainbow trout and their products can be stored frozen at temperature under $-18^{\circ} \mathrm{C}$ for a period of 6 months and to be analyzed within this term for determination of residues from enrofloxacin. For common carp meat, this period is 3 months. Administration of the drugs in modern aquaculture including antibiotics, requires knowledge for the withdrawal time of the drugs in each fish species. Freezing for months of whole and eviscerated fish results in different levels of fluoroquinolones in the muscles. Less residues are found in eviscerated fish during storage at $15,16,17^{\circ} \mathrm{C}$. A strong tendency toward enrofloxacin and ciprofloxacin decrease was observed in trout and carp muscles, although these drugs can be found in the samples after months of storage.

\section{ACKNOWLEDGEMENTS}

This research was financially supported by Faculty of Veterinary Medicine, Trakia University, Project 19/2011.

\section{REFERENCES}

1. Currie, D., Lynas, L., Kennedy, D.G., McCaughey, W.J. (1998). Evaluation of a modified EC Four Plate Method to detect antimicrobial drugs. Food Addit. Contam. 15, 651-660. http://dx.doi.org/10.1080/02652039809374694 PMid:10209575

2. Samanidou, V.F., Evaggelopoulou, E.N. (2007). Analytical strategies to determine antibiotic residues in fish. J. Sep. Sci. 30, 2549-2569. http://dx.doi.org/10.1002/jssc.200700252 PMid:17924582

3. Haritova, A., Fink-Gremmels, J. (2010). An in silico model for the prediction of muscle: plasma partition coefficients of feed contaminants. Book of Abstracts. $2^{\text {nd }}$ Feed for Health Conference, p. 48. Tromso, Norway

4. Liang, J., Li, J., Zhao, F., Liu, P., Chang, Z. (2012). Pharmacokinetics and tissue behavior of enrofloxacin and its metabolite ciprofloxacin in turbot Scophthalmus maximus at two water temperatures. Chinese J. Oceanol. Limnol. 30, 644-653.

http://dx.doi.org/10.1007/s00343-012-1228-2

5. Alfredsson, G., Ohlsson, A. (1998). Stability of sulphonamide drugs in meat during storage. Food Addit. Contam. 15, 302-306.

http://dx.doi.org/10.1080/02652039809374645 PMid:9666889

6. Verdon, E., Fuselier, R., Hurtaud-Pessel, D., Couedor, P., Cadieu, N., Laurentie, M. (2000). Stability of penicillin antibiotic residues in meat during storage: ampicillin. J. Chromatogr. A. 882, 135-143.

http://dx.doi.org/10.1016/S0021-9673(00)00065-0 
7. Pavlov, A., Vachin, I., Lashev, L. (1993a). Studies on amoxicillin residues in chicken meat and by-products during storage. Vet. Nauki 2, 94-98.

8. Dinkov, D., Pavlov, A., Lashev, L. (1998). Kinetics of the residue levels of kanamycin and trimethoprim in poultry meat at storage. Bulg. J. Vet. Med. 1, 105-112.

9. Pavlov, A., Lashev, L., Rusev, V. (2006). Studies on the residue levels of tobramycin in stored poultry products. Trakia J. Sci. 3, 20-22.

10. Pavlov, A., Vachin, I., Lashev, L., Tododrov, B. (1993b). Influence of the irradiation of rabbit meat on unbound ampicillin and gentamicin content. Soz. EpHefte 16, 155-157.

11. EMEA/MRL/820/02-FINAL (2002). Enrofloxacin (Extension to all food producing species): Summary report (5) Committee for Veterinary Medicinal Products,

http://www.ema.europa.eu/ema/index.jsp?curl=pages /includes/document/document detail.

12. Lucchetti, D., Fabrizi, L., Guandalini, E., Podesta, E., Marvasi, L., Zaghini, A., Coni, E. (2004). Long depletion time of enrofloxacin in rainbow trout (Oncorhynchus mykiss). Antimicrob. Agents Chemother. 48, 3912-3917.

http://dx.doi.org/10.1128/AAC.48.10.3912-3917.2004 PMid:15388452 PMCid:PMC521881

13. EPA (2010). Stability of Pharmaceuticals, Personal Care Products, Steroids, and Hormones in Aqueous Samples, POTW Effluents, and Biosolids. United States Office of Water Environmental Protection Agency (4303).
14. Okerman, L., Van Hende, J., De Zutter, L. (2007). Stability of frozen stock solutions of beta-lactam antibiotics, cephalosporins, tetracyclines and quinolones used in antibiotic residue screening and antibiotic susceptibility testing. Anal. Chim. Acta 586, 284-288.

http://dx.doi.org/10.1016/j.aca.2006.10.034

PMid: 17386725

15. Xu, W., Zhu, X., Wang, X., Liping, D., Gan, Z. (2006). Residues of enrofloxacin, furazolidone and their metabolites in Nile tilapia (Oreochromis niloticus). Aquaculture 254, 1-8. http://dx.doi.org/10.1016/j.aquaculture.2005.10.030

16. Fang, W., Zhou, S., Yu, H. (2007). Pharmacokinetics and tissue distribution of enrofloxacin and its metabolite ciprofloxacin in Scylla serrata following oral gavage at two salinities. Aquaculture 272, 180-187.

http://dx.doi.org/10.1016/j.aquaculture.2007.08.049

17. Xu, L., Wang, H., Yang, X., Lu, L. (2013). Integrated pharmacokinetics/pharmacodynamics parametersbased dosing guidelines of enrofloxacin in grass carp Ctenopharyngodon idella to minimize selection of drug resistance. BMC Vet. Res. 9, 126. http://dx.doi.org/10.1186/1746-6148-9-126 PMid:23800340 PMCid:PMC3717066

18. Al-Dgither, S., Alvi, S.N., Hammami, M.M. (2006). Development and validation of an HPLC method for the determination of gatifloxacin stability in human plasma. J. Pharm. Biomed. Anal. 41, 251-255. http://dx.doi.org/10.1016/j.jpba.2005.09.026 PMid:16311002 